\title{
Accuracy Assessment of Low Cost UAV Based City Modelling for Urban Planning
}

\author{
Ramazan Cuneyt ERENOGLU, Oya ERENOGLU, Niyazi ARSLAN
}

\begin{abstract}
This paper presents an Unmanned Aerial Vehicles (UAV) based 3D city modelling approach to be used in managing and planning urban areas. While the urban growth is rapidly increasing in many places of the world, the conventional techniques do not respond to the changing environment simultaneously. For effective planning, high-resolution remote sensing is a tool for the production of 3D digital city models. In this study, it is aimed at designing the remote sensing by UAV through urban terrain. Using all the information produced from UAV imagery, high-accurate 3D city models are obtained. The analysis of XYZ data of the derived from 3D model using UAV photogrammetry revealed similar products as the terrestrial surveys which are commonly used for the last development plans and city maps. The experimental results show the effectiveness of the UAV-based 3D city modelling. The assessed accuracy of the UAV photogrammetry proved that urban planners can use it as the main tool of data collection for boundary mapping, changes monitoring and topographical surveying instead of GPS/GNSS surveying.
\end{abstract}

Keywords: aerial survey; municipal zoning bylaws; public safety; 3D city model; unmanned aerial vehicle; urban design

\section{INTRODUCTION}

The percentage of the population living in cities of more than half of the world will exceed $75 \%$ over the next 30 years [1]. Considering that more than a few million people have moved to the city each month, urban growth is the fastest phenomenon in the developing world [2]. In the face of continuous-increasing population and size of cities, this is expected to be a compatible development and planning from the environmental, spatial and social aspects [3]. The utilization of the latest technology which provides for a high accuracy and speed, for collecting of 3D geographical data in real-time is so critical. With the $3 \mathrm{D}$ data produced through this technology, the possibility of evaluation and monitoring of urban changes is provided [4]. For example, monitoring built-up areas, updating development plan and detecting illegal buildings can be performed using the feature extraction from the produced 3D model [5].

The planners need high-accurate 3D terrain and surface models of urban area to improve their performance for urban domains $[6,7]$. For the 3D digital city, highresolution image is one of the most important information sources [8-10]. The terrain modelling is experiencing significant advances thanks to the availability of improved methodologies and cost-effective instruments for data acquisition and analysis, such as Unmanned Aerial Vehicles (UAV), that demonstrated to compete with traditional data acquisition platforms, such as aircraft and satellite, due to high spatial resolution of imagery, high operational flexibility and low operational costs. [11-14]. It has potential uses in the planning stages as well as many views of urban life $[15,16]$. The rapidly developing technology of UAV is a low-cost data collection tool with the availability of planners $[17,18]$. As the main method of data capture for topographical surveying and boundary mapping, UAV photogrammetry can especially replace GPS/GNSS surveying [19]. After these technological advances, technical and legal arrangements have also been made as required by urban planners [20].

Aerial images taken on UAV and using low cost software can be used to produce accuracy of photogrammetric products for most of the engineering purposes [18]. Obviously the labour needed with land survey topographic works is significantly more extensive than with UAV photogrammetry. Moreover, the cost of satellite or manned aircraft images is higher than the cost of the UAV imagery. While interactive design and planning will still be of need and value, a detailed accuracy assessment should find more interest. In this study, an accuracy assessment, therefore, will be performed for the UAV-assisted spatial modelling to reflect the quality of the digital land models which will be used by urban planners. The results from UAV photogrammetry will be compared with ones from the RTK/GNSS, CORS and other terrestrial surveying to gain the insight into the modelling efficacy in accuracy and time domains. Here, the UAV-assisted modelling is focused to create high-accurate digital terrain model. By instantly producing digital land models, the proposed approach can be used to monitor zoning activities in urban or non-urban areas by urban planners. Considering the policy of the regulation, application and permission in many countries around the world, UAV photogrammetry provides more efficient, faster and economical solutions than terrestrial methods, aircraft and satellite [18]. Moreover, natural hazard damages can be mapped using UAV which is a safe and efficient way of taking highresolution images.

\section{RELATED WORK}

3D modelling and visualization is a rapidly developing area for urban planning and modelling. Many more efficient and effective methods developed by the researchers to create three-dimensional city models are available [21]. These can be grouped into automatic, semiautomatic and manual methods. While the automatic approach extracts 3D natural and artificial objects from satellite or aerial images by using image processing technologies, the semiautomatic approach creates 3D objects separately based on the technological support such as photogrammetry and $3 \mathrm{D}$ vision. On the other hand, the manual approach produces all the geometries of an object one by one in a commercial software package.

Photogrammetry is a semiautomatic object of the technologies commonly used in extracting 3D geometries. It can be used for both ground and aerial images. The ground and aerial images are used to extract the details and 
the forms of buildings, respectively [22]. The desired attributes of object are obtained from multi-image photogrammetry (or structure from motion). An advantage of ground-based photogrammetry (close-range) is that taking photos does not cost much. However, there are some disadvantages. For example, it may be difficult to overlap and match the two photos with different white balances on the same sides of building. In summary, ground-based photogrammetry is useful especially for extracting geometric details of the buildings.

Another approach is to use UAV- photogrammetry modelling. It is advantageous because it needs only a few images [23]. Without the fixed colour balancing of image, the textures of buildings are extracted from the photo. The satellite and aircraft photogrammetry are more costly methods than the ground-based techniques when considering their installation, operation and data collection costs. On the other hand, the unmanned aerial vehicle is now a cheaper alternative to conventional aerial carrier platform.

From 2D aerial stereo images, a semi-automatic approach for creating 3D topologically structured data has been developed [24]. In order to acquire 3D point cloud data and to build a very high resolution $3 \mathrm{D}$ city model, the UAV-assisted stereo pair images have been used as raw data $[25,26]$. The UAV technology has made significant progress in system development and hardware in last decade; therefore, it is an important tool for surveying and mapping. Especially, data acquisition can be performed for very high resolution city modelling carrying off-the-shelf digital cameras and/or other sensor systems [27].

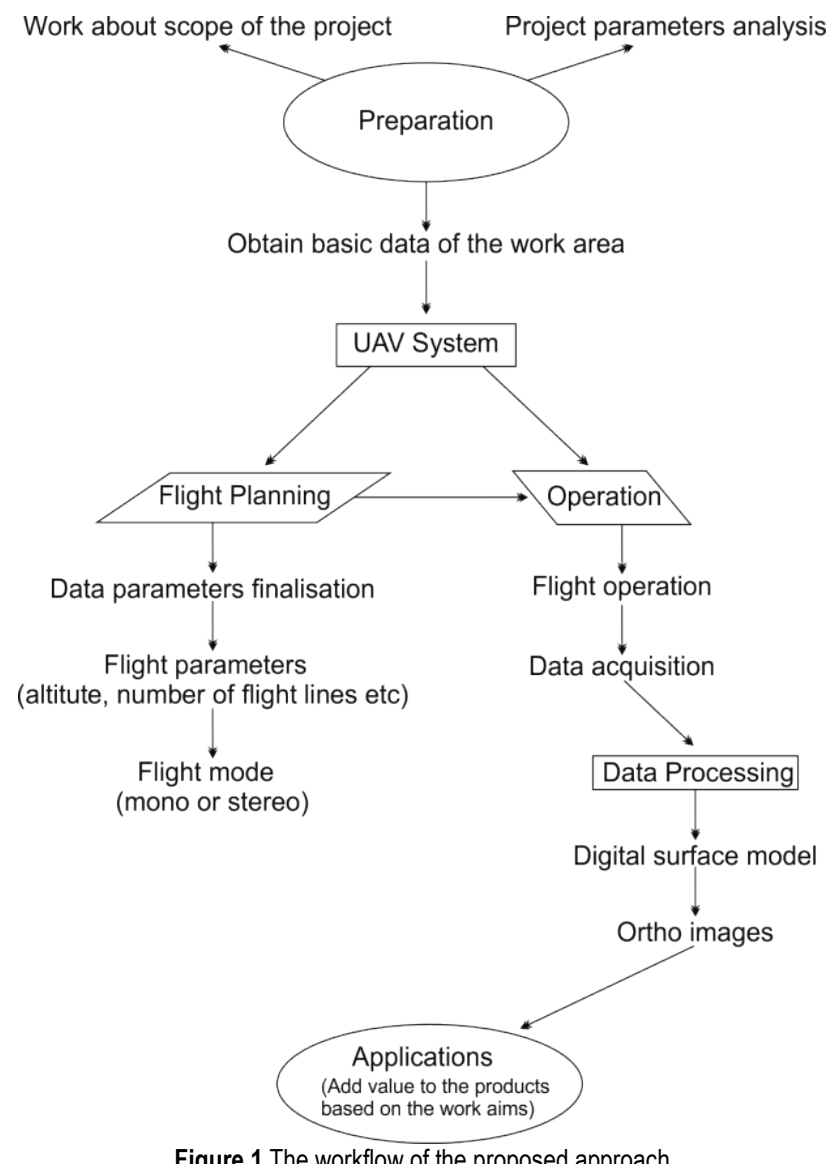

Figure 1 The workflow of the proposed approach

\section{PROPOSED METHODOLOGY}

The proposed procedure can be summarized as follows: (a) Camera calibration scheme, (b) UAV-based data acquisition, (c) UAV imagery triangulation, (d) Production of the data cloud, (e) Integration of UAV point data to GPS/GNSS geo-reference and adjust the point cloud data, (f) Modelling of DTM, (g) Texturing model from aerial imagery, (h) Quality control using GPS/GNSS, CORS and terrestrial surveys. Fig. 1 shows the workflow structure for introducing the proposed method in this study.

\section{EXPERIMENTAL STUDY}

In this study, the low-cost and flexible UAV was used as the carrier platform in order to collect the aerial imagery. A brief summary of the used platform and other equipment is given below:

- UAV: Mikrocopter Octocopter XL 8 multi-rotor control platform with gyroscope and GNSS antenna, MK3538 - black brushless motors, IR camera trigger, MK SLR2 camera gimbal, video transmission system. It is equipped with LiPo batteries with a capacity of $11000 \mathrm{mAh}$. The weight of main body is $2.0 \mathrm{~kg}$, the weight of digital camera with lens is $0.250 \mathrm{~kg}$ and the weight of battery is $0.8 \mathrm{~kg}$.

- Sensor System: Canon EOS-M Mirrorless Digital Camera, 18.0 megapixels, CMOS sensor $(22.3 \times 14.9$ $\mathrm{mm}), 18-55 \mathrm{~mm}$ lens, time lapse software.

- GPS/GNSS Receiver: Satlab SL500 dual-frequency instrument has a manufacturer's stated accuracy specification of $\pm 1 \mathrm{~cm}+1$ ppm RMS horizontal, and $\pm 2 \mathrm{~cm}+1$ ppm RMS vertical.

- Total station: Kolida KTS-442 RLC with the following technical performance: precision angular measurements 1 ", distance measurements reflectorless $5 \mathrm{~mm}+3 \mathrm{ppm}$ up to $600 \mathrm{~m}$, typical measurement times $0.5 \mathrm{~s}$.

Camera calibration is also important for any photogrammetric study since high-accurate digital modelling requires well calibrated cameras [28]. In other words, a calibrated camera provides information about the used camera that improves accuracy for the modelling studies. It is a process of determining the characteristics of a camera so it can be used as a measurement device. This determination needs to be created only once and it is used for consecutive project. For this study, the calibration of the Canon EOS-M digital camera was performed using AgisoftPhotoscan in camera calibration module based on several images of a calibration grid [29]. Before producing $3 \mathrm{D}$ modelling, the CCD format size of a digital camera $\left(F_{\mathrm{w}}\right.$, $\left.F_{\mathrm{h}}\right)$, the focal length of the lens $(f)$, the lens distortions $\left(k_{1}\right.$, $k_{2}, k_{3}$, and $\left.p_{1}, p_{2}\right)$ and the principal points $\left(X_{\mathrm{p}}, Y_{\mathrm{p}}\right)$ were successfully determined as the characteristics specifications of the digital camera using the software tool. Finally, the calibration status report was obtained, and inserted in the software.

A major effort was devoted towards setting up a pilot project with the aim to collect very high resolution aerial imagery over the Canakkale Onsekiz Mart University (COMU) campus area, Canakkale, NW Turkey (Figs. 2(a) and (b)). The flying mission was performed to collect the 
aerial images on December $4^{\text {th }}, 2015$. The UAV-Okto XL used to fly in an autonomous mode (Figs. 2(c) and (d)). Before flight mission the operator needs to test all the electronic parts of UAV to see whether every part is working properly.
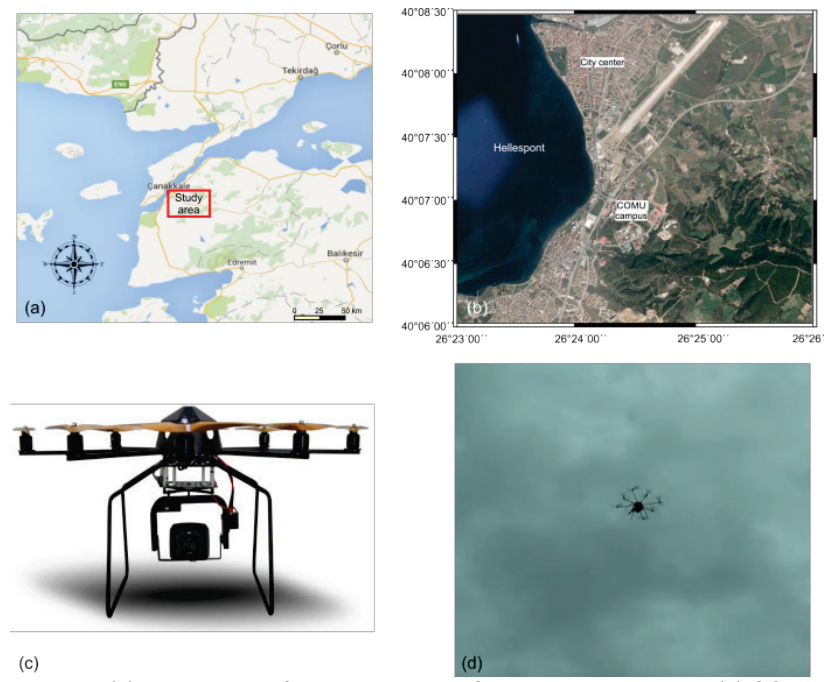

Figure 2 (a) Localization of the study area in Canakkale, NW Turkey, (b) COMU Campus area in Canakkale, (c) The octocopter XL used in this study, (d) A snapshot from the flight.

For a successful flight operation, it is very critical to be aware of potential problems on UAV. For safe flight, the GPS onboard, rudder, elevator and main frame, digital camera, camera mount, propeller, electronic speed controller and remote controller should be checked before the flight. A suitable location is provided for launching operation after all tests have been performed. For flight planning step, the working area and suitable locations for starting and landing were chosen. Fig. 3 shows the predefined waypoints of the flight planning in Google KML format. The distance between 4 parallel neighbouring flight lines was planned with $40 \mathrm{~m}$ which equates strip and across-strip overlaps of about $80 \%$ and $60 \%$, respectively. Note that the autonomous flight mission was preferred to capture images by digital camera in this study. The flying duration was approximately 18 minutes. Note that operational time depends on additional loading weights and the weather conditions.

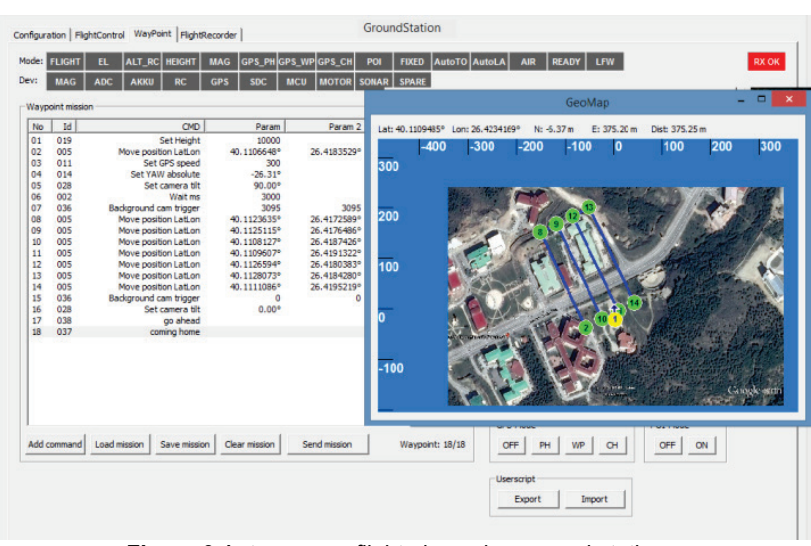

Figure 3 Autonomous flight plan using ground station

For the modelling area $(400 \times 500 \mathrm{~m}), 152$ images were taken at a flying height of 100 metre in total with a pixel size of $2.3 \mathrm{~cm}$ depending on the flying height and the size of mapping area. Fig. 4 shows such a sample of small sub-block.

The processing of UAV images has had its own challenges in the last decade. Inertial Measurement Unit (IMU) and Ground Control Points (GCP) are required as input to obtain processed UAV images. Precise timetagging of the camera shutter precisely within the GPS time-scale is the prerequisite for annotating the acquired imagery with the position and attitude information derived from the on-board GPS/GNSS and Inertial Measurement Unit (IMU). After calibration, this allows to use the direct sensor orientation in the processing $[30,31]$.
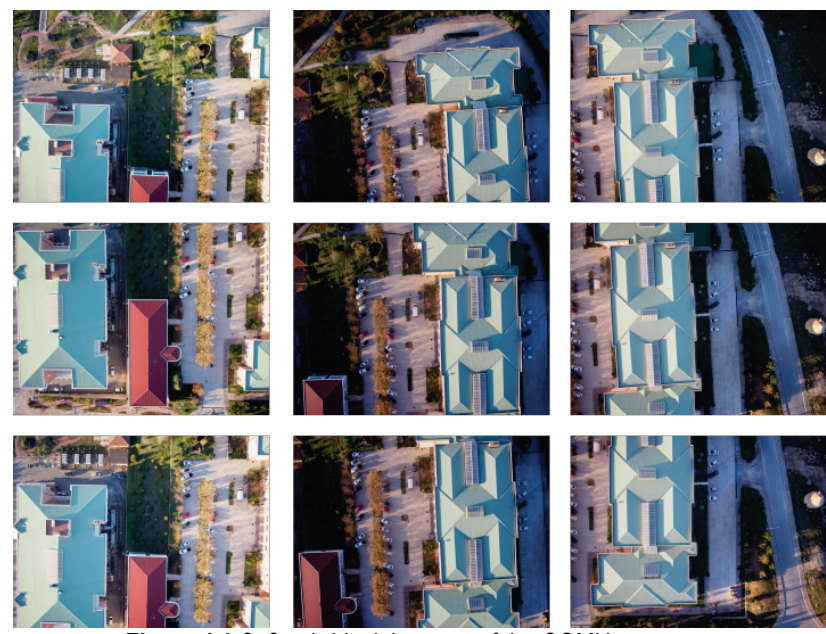

Figure $4 \mathrm{~A} 3 \times 3$ sub-block imagery of the COMU campus.

Table 1 Geo-coding IMU data
\begin{tabular}{|c|c|c|c|}
\hline Image \# & Roll $\left({ }^{\circ}\right)$ & Pitch $\left({ }^{\circ}\right)$ & Yaw $\left({ }^{\circ}\right)$ \\
\hline PC040041 & 0.53 & 0.43 & -20.21 \\
\hline PC040042 & 3.88 & 2.12 & -23.00 \\
\hline PC040043 & 6.16 & -4.61 & -24.31 \\
\hline PC040044 & 7.98 & -4.04 & -25.51 \\
\hline PC040045 & 8.69 & -5.27 & -27.44 \\
\hline PC040046 & 8.64 & -2.41 & -25.39 \\
\hline PC040047 & 6.67 & -5.22 & -26.84 \\
\hline PC040048 & 7.82 & -6.30 & -25.31 \\
\hline PC040049 & 8.36 & -5.24 & -26.31 \\
\hline PC040050 & 8.51 & -5.42 & -26.78 \\
\hline PC040051 & 8.48 & -4.15 & -27.91 \\
\hline PC040052 & 7.68 & -4.56 & -26.85 \\
\hline PC040053 & 10.33 & -3.00 & -26.26 \\
\hline PC040054 & 11.64 & 0.74 & -26.66 \\
\hline
\end{tabular}

Tab. 1 shows some of the geo-coding IMU data during the flying mission. For ground control points during the field campaign, the targeted ground control points were established to align 3D models and to control the UAV photogrammetry. The location of all the points was selected to appear in aerial images. The GNSS receivers were utilized to position at the centre of the targets, and 30 ground control points were surveyed terrestrially by RTK GPS/GNSS and CORS surveys for the global referencing in WGS84. For each GCP, 10 observation epochs were collected and the average value of 10 epochs was recorded as the surveyed coordinate of the related GCP. Consequently, the achievable accuracy was realized as a few centimetres for the GCP coordinates. Note that the corrections of the VRS approach were considered for the CORS surveys. As a rover antenna, the SATLAB SL 500 type GNSS receiver was used. The correction of rover receiver was sent via GSM. This large number of GCPs 
will provide a redundant registration in the processing software, as well as a profound quality control using the results from the RTK GPS/GNSS and CORS surveys.

The next step was image evaluation after data acquisition. The UAV images were processed using AgisoftPhotoscan Professional Software in order to produce 3D digital terrain model. This software uses a combination of Structure-from-Motion (SfM) and MultiView-Stereo (MVS). It is a computer vision technique that automatically constructs $3 \mathrm{D}$ models using images. In addition, it has been well developed for the stage of image processing such as camera calibration, triangulating image blocks using measured tie points, digitizing and texturing 3D features.

The automatic detection of characteristic points was performed on each aerial image as the first step of reconstruction of the image acquisition. In this stage, the GCPs were flagged to each image and the images were aligned in an absolute $3 \mathrm{D}$ space. The result is a reconstruction of the image and all matched feature points are accurately positioned in the $3 \mathrm{D}$ coordinate system. The features were matched for relating each point with its equivalent in other images. In this step, the maximum likelihood estimation performed the iterative bundle adjustment using the size of each image and the focal length. By projecting the pixels of each aligned image, the 3D sparse point cloud including 276.966 generated points was produced. The relative camera locations of each image and the sparse point cloud above the study area are given in Fig. 5 (a). A dense point cloud was calculated using different depth maps combined in a single scene based on the position, orientation and focal length of each image frame. The dense point cloud consists of 36.129.484 points (Fig. 5(b)). The 3D mesh and triangular models were constructed by the triangulation of the point cloud (Fig. 5(c) and Fig. 5(d)). The produced 3D model included 2.408 .632 faces.
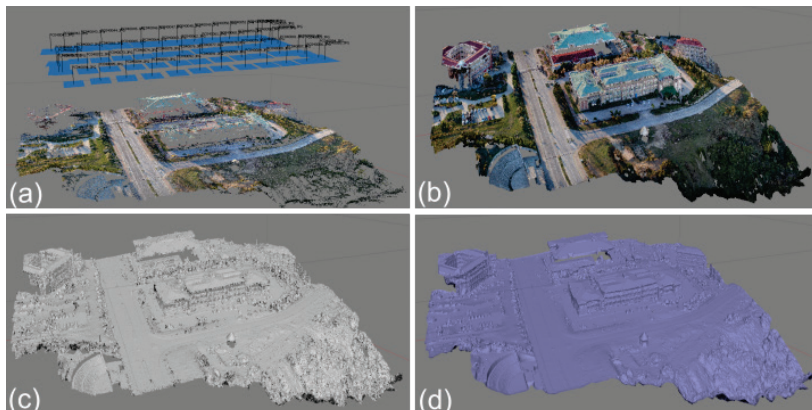

Figure 5 (a) The relative locations of each of the images recorded (represented with blue rectangles) above point cloud derived for the study area, (b) 3D Dense point cloud, (c) 3D mesh model, (d) 3D triangular models.

Finally, the texture projection was performed to appear more photorealistic in the $3 \mathrm{D}$ reconstruction processing. For this purpose, by projecting the images on the geometric framework of the model, the texture map was produced using a weight distance function of the true colours. Some examples of the final textured 3D models were presented in Fig. 6. Note that the Photoscan software performed the assignment process of a colour value in $2 \mathrm{D}$ to a $3 \mathrm{D}$ geometry using UV-mapping procedure [32]. In a texture map, $\mathrm{u}$ and $\mathrm{v}$ coordinates in 2D space are basically connected to $3 \mathrm{D}(x, y$ and $z)$ coordinates.
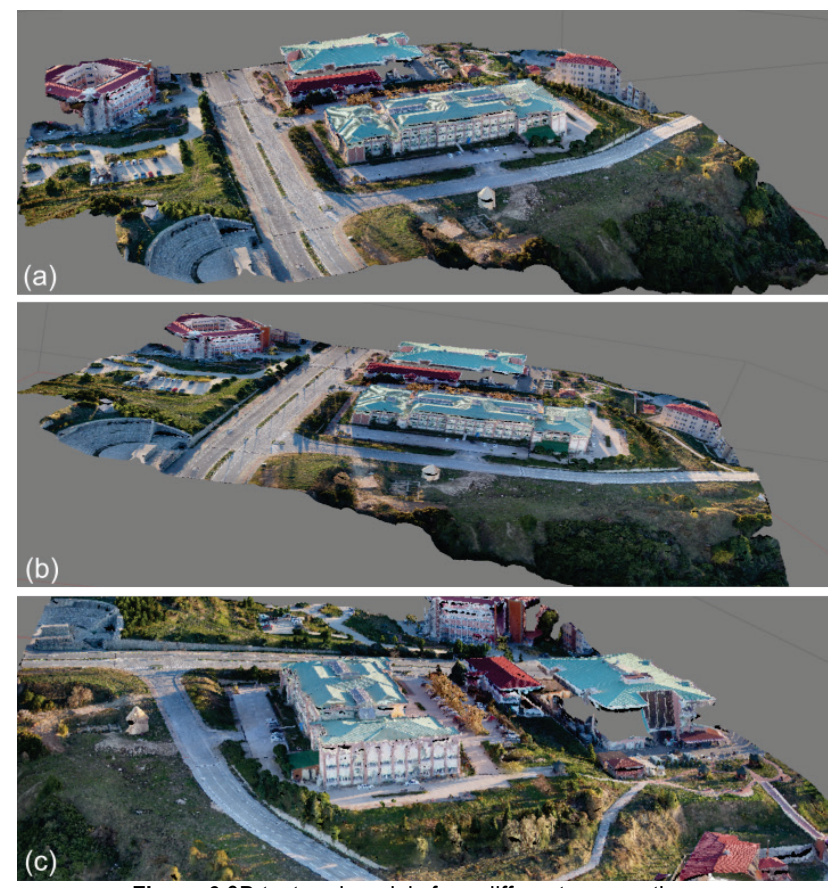

Figure $63 \mathrm{D}$ textured models from different perspectives.

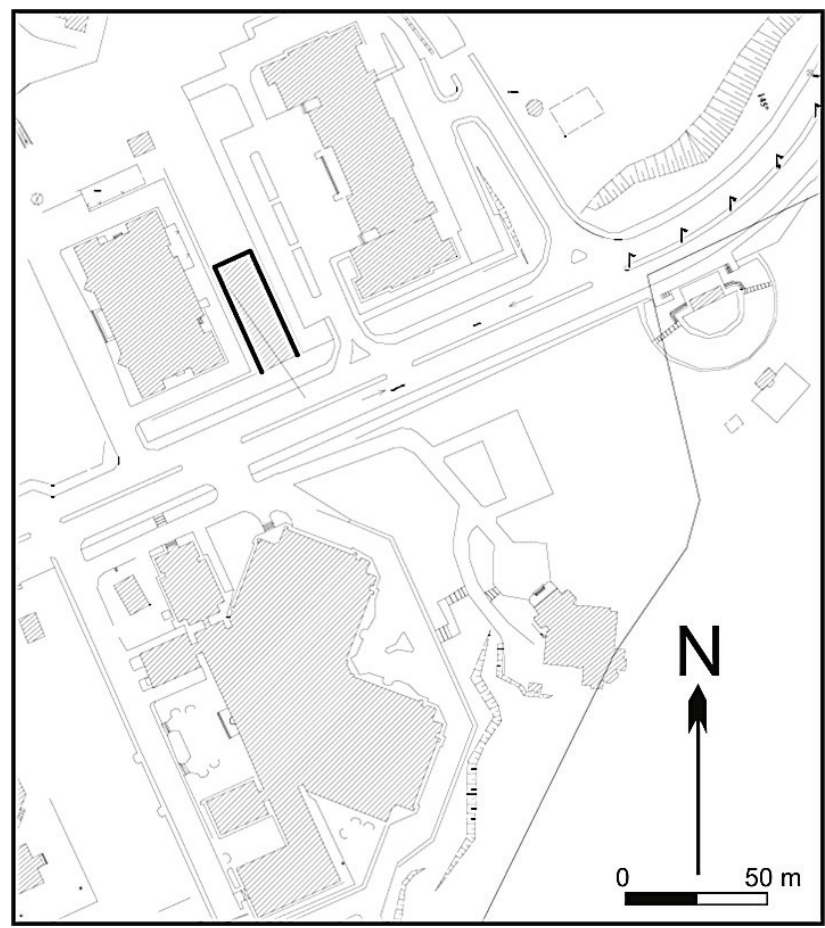

Figure $72 \mathrm{D}$ reconstruction plan obtained from UAV photogrammetry.

The created 3D digital models can be used for producing 2D cadastral and transportation map updates successfully. The resulting geo-referenced orthophoto and DEM were imported into ArcMap to obtain cadastral map $[8,33]$. Thereby, Fig. 7 shows the cadastral map of COMU campus area obtained from the $3 \mathrm{D}$ digital terrain model. The accuracy assessment for the cadastral map from UAV imagery and finally a comparison with the results from tape measurement was performed. First, the same control distances were measured by a steel measuring tape. Then, the same distances were also obtained from the cadastral map. The UAV-based cadastral map and the surveyed distances clearly show that the lines have almost overlapped. Moreover, the results of UAV-model measurements were compared against results from tape 
surveying as a further quality check. The difference results are close to each other in the $\mathrm{cm}$ level, up to $2 \mathrm{~cm}$.

\section{$5 \quad$ RESULTS AND DISCUSSION}

UAV-assisted digital photogrammetry based on structure from motion (SfM) algorithms was used to derive a very high spatial resolution DSM and orthophoto mosaic $[34,35]$. Dense surface model and the other sub-models obtained from digital imagery are given in the previous sections. To test the accuracy of the 3D model derived by $\mathrm{UAV}$, the coordinates of 3D model were compared with the ones from RTK/GNSS and CORS surveys. For this purpose, 30 ground control points were surveyed as check point. Tab. 2 shows the errors in the coordinates between Orthophoto/DEM and RTK/GNSS surveys. The errors in $X$ and $Y$ components are in a few centimetres level. The coordinates of 3D models are compatible with the ones by RTK/GNSS.

Table 2 The dataset of measured errors between the Orthophoto/DEM and RTK/GNSS surveys, and between the Orthophoto/DEM and CORS surveys for the target centres.

\begin{tabular}{|c|c|c|c|c|}
\hline \multirow[t]{2}{*}{ Point \# } & \multicolumn{2}{|c|}{$\begin{array}{c}\text { Differencesof } \\
\text { [Orthophoto-RTK] }\end{array}$} & \multicolumn{2}{|c|}{$\begin{array}{c}\text { Differencesof } \\
\text { [Orthophoto-CORS] }\end{array}$} \\
\hline & $X(\mathrm{~m})$ & $Y(\mathrm{~m})$ & $X(\mathrm{~m})$ & $Y(\mathrm{~m})$ \\
\hline 1 & 0.010 & -0.021 & 0.028 & -0.022 \\
\hline 2 & -0.021 & 0.015 & 0.026 & 0.013 \\
\hline 3 & -0.006 & -0.025 & -0.018 & -0.010 \\
\hline 4 & 0.026 & -0.017 & -0.046 & -0.014 \\
\hline 5 & 0.037 & -0.019 & 0.036 & 0.010 \\
\hline 6 & -0.010 & -0.023 & 0.018 & -0.014 \\
\hline 7 & 0.022 & -0.020 & 0.023 & 0.025 \\
\hline 8 & -0.016 & -0.018 & -0.018 & -0.019 \\
\hline 9 & 0.014 & 0.023 & -0.031 & -0.023 \\
\hline 10 & -0.047 & -0.012 & 0.024 & 0.015 \\
\hline 11 & 0.020 & 0.021 & -0.027 & -0.018 \\
\hline 12 & 0.004 & -0.005 & -0.017 & 0.023 \\
\hline 13 & 0.005 & -0.030 & -0.024 & -0.015 \\
\hline 14 & 0.024 & 0.020 & 0.015 & -0.032 \\
\hline 15 & -0.015 & 0.011 & 0.018 & -0.027 \\
\hline 16 & -0.018 & 0.006 & -0.027 & -0.042 \\
\hline 17 & -0.025 & 0.010 & 0.030 & -0.023 \\
\hline 18 & -0.033 & 0.026 & 0.021 & 0.028 \\
\hline 19 & -0.014 & -0.011 & 0.037 & 0.013 \\
\hline 20 & 0.016 & 0.005 & -0.024 & -0.018 \\
\hline 21 & -0.011 & -0.013 & -0.016 & -0.013 \\
\hline 22 & -0.027 & -0.012 & -0.015 & 0.025 \\
\hline 23 & 0.021 & 0.043 & -0.032 & -0.018 \\
\hline 24 & -0.014 & -0.015 & -0.020 & -0.011 \\
\hline 25 & -0.020 & -0.028 & -0.019 & 0.021 \\
\hline 26 & -0.015 & 0.035 & -0.048 & 0.025 \\
\hline 27 & -0.016 & 0.027 & -0.017 & -0.050 \\
\hline 28 & 0.018 & -0.022 & 0.015 & 0.012 \\
\hline 29 & -0.025 & 0.012 & -0.034 & -0.020 \\
\hline 30 & -0.033 & 0.025 & -0.023 & 0.019 \\
\hline
\end{tabular}

Furthermore, Tab. 2 shows also the coordinate errors in $X$ and $Y$ components between the 3D model and CORS surveys. There is a similar trend in the difference between the coordinates. The mean and standard deviations of these errors were calculated to make a more concrete comparison between the coordinates of 3D model and GNSS surveys. For 3D model, the mean values of the errors in $X$ components between RTK/GNSS and CORS surveys are $-0.0050 \mathrm{~m}$ and $-0.0055 \mathrm{~m}$, respectively. The mean values of the errors in $Y$ components between RTK/GNSS and CORS surveys are $-0.0004 \mathrm{~m}$ and $-0.0053 \mathrm{~m}$, respectively. It seems that there is a little difference on the mean values due to possible random errors. Finally, the standard deviations were computed between the $3 \mathrm{D}$ model and GPS/GNSS surveys. For 3D model, the standard deviations of the errors in $X$ components between RTK/GNSS and CORS surveys are $0.0214 \mathrm{~m}$ and $0.0262 \mathrm{~m}$, respectively. These are so accurate results. For 3D model, the standard deviations of the errors in $Y$ components between RTK/GNSS and CORS surveys are $0.0212 \mathrm{~m}$ and 0.0222 $\mathrm{m}$, respectively. The results for CORS surveys are relatively greater than the ones for RTK/GNSS. The possible reason is the closeness of the reference station for RTK/GNSS technique with respect to the ones of CORS surveys.

For the geometric accuracy assessment of building height estimation, a building reconstruction method from UAV-based 3D model was evaluated in detail. For this purpose, the UAV carrier platform was used to get the high resolution digital images of the city in order to derive 3D city models and textures of buildings. Here, it is aimed to analyze the 3D model for building heights created from the 3D city models. For this purpose, a building facade was selected over the created 3D model. Here, a calibrated Kolida KTS-442 RLC total station was used to obtain precise observations using conventional terrestrial technique without reflectors (Fig. 8).

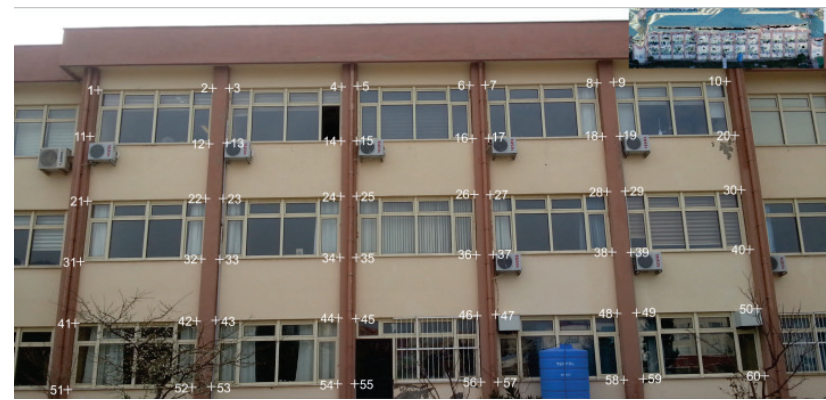

Figure 860 corner points on the building facade and 3D model of the same facade at the upper right corner
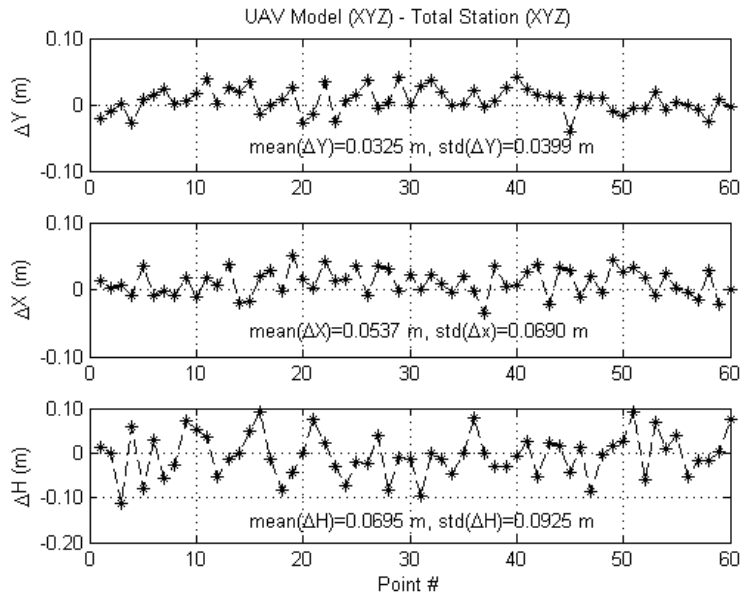

Figure 9 The coordinate differences between UAV model and total station surveys.

A calibrated Kolida KTS-442 RLC total station was located on the known reference points. The coordinates of 60 corner points on the building facade were surveyed using the total station. In addition, there are previously the model coordinates of the same corners from the existing 3D digital terrain model. Now, the quality of dataset of 3D model coordinates will be analysed comparing the results 
of terrestrial surveying. The difference of the coordinates between UAV 3D model and total station surveys can be seen in Fig. 9, along with their means and standard deviations.

The evaluation of the dataset proved that the variations were a few centimetres for horizontal components, and were up to 9 centimetres for the height component. In such a case, it verifies that both the horizontal and height coordinates of the total station have higher accuracy than UAV-assisted 3D model.

\section{CONCLUSIONS}

The urban planning has to deal with immediate needs and problems in the rapidly growing world; it has a responsibility to the future generations as well as the public. The planners must do the necessary work and take the precautions in the general public interest. They preserve or advance the public interest by respecting the diversity, needs, values and aspirations of the general public. For this purpose, the geographic data is collected for land use and urban development by different surveying techniques. Nowadays, the planners integrate potential application of unmanned aerial systems into current municipal land use control by-laws. Especially, the variable of land use classification is building height for municipal zoning by-law tools. The unmanned aerial systems were used to create 3D virtual city models for urban planning effectively, fast and economically in the last decade.

The UAV is a highly adaptable technology that is constantly changing in innovative ways in order to provide greater utility. It provides aerial imagery data by which the planners can better inform the public by the latest way. In this study, the reconstruction of 3D models of the COMU campus was investigated in terms of accuracy. A large number of aerial images were taken by the requirement to produce a virtual reconstruction of this area. These images were taken with an Octo XL UAV. The images were processed in a workflow based on SfM/MVS and GCPs were surveyed with a GPS/GNSS technology. This resulted in mean absolute errors up to a few centimetres. Moreover, the ability of a UAV-based 3D model to produce coordinates at similar accuracies to RTK GPS/GNSS and CORS survey techniques in both planar and attitude components is significant. Especially, the results of the experiments for building facade surely confirmed the achievable accuracy by UAV technology. In summary, total cost of the experiments is approximately 2,500 USD. UAV photogrammetry can provide reliable horizontal accuracy. In addition, vertical accuracy requires ground control point to be reliable results. Here, the vertical accuracy was obtained in level of centimetre through 30 ground control points that were surveyed terrestrially by RTK GPS/GNSS and CORS surveys. The UAV-assisted 3D modelling is extremely costly and time efficient approach. Moreover, it can fill in the gap of existing technology for urban planning. Consequently, the proposed approach can be easily adapted to different 3D modelling applications. In addition, it is recommended to use the proposed approach for mapping damages safely and efficiently after natural hazards. The processing parameters strongly depend on a large number of variables to be selected. Moreover, these parameters are the camera characteristics, the image scale, the quality of the imagery, the size and volume of the area to be modelled, hardware capacity and so on. A rough 3D model was created as LoD1 and a more detailed 3D model was generated for each separate structure as LoD-2, LoD-3 and LoD-4.

\section{REFERENCES}

[1] (2014). World Urbanization Prospects: The 2014 Revision. United Nations Department of Economic and Social Affairs, Population Division. https://esa.un.org/unpd/wup/ Publications/Files/WUP2014-Report.pdf/, （accessed 17.04.17).

[2] (2010). BIG's proposal for the Audi Urban Future Award. ArchDaily. http://www.archdaily.com/77103/bigs-proposalfor-the-audi-urban-future-award/, (accessed 03.01.16).

[3] Schmitt, G. (2012). A planning environment for the design of future cities, in: S. Mueller-Arisona, G. Aschwanden, J. Halatsch, P. Wonka (Eds.), Digital Urban Modeling and Simulation. Communications in Computer and Information Science, Springer-Verlag, Berlin, Heidelberg, 3-36. https://doi.org/10.1007/978-3-642-29758-8_ 1

[4] Wang, T. (2003). Interdisciplinary urban GIS for smart cities: advancements and opportunities, Geo-Spatial Information Sciences, 16(1) 25-34. https://doi.org/10.1007/s11806-009-0170-8

[5] Mueller-Arisona, S., Zhong, C., Huang, X., \& Qin, R. (2013). Increasing detail of 3D models through combined photogrammetric and procedural modeling. Geo-Spatial Information Sciences, 16(1), 45-53. https://doi.org/10.1080/10095020.2013.774102

[6] Tahar, K. N. \& Ahmad, A. (2012). A simulation study on the capabilities of rotor wing unmanned aerial vehicle in aerial terrain mapping. Int. J. Phys. Sci., 7, 1300-1306.

[7] Stal, C., De Wulf, A., De Maeyer, A. P., Goossens, R., Nuttens, T., \& Tacki, F., 2012. Statistical comparison of urban 3D models from photo modeling and airborne laser scanning. Proc. International Multidisciplinary Scientific GeoConference, SGEM, Albena, Bulgaria, p. 8.

[8] Cunningham, K., Walker, G., Stahlke, E., \& Wilson, R., (2011). Cadastral audit and assessments using unmanned aerial systems. Proc. ISPRS and UAV-g, Zurich, Switzerland, pp. 213-216.

[9] Gruen, A. \& Wang, X. (1998). CC-Modeler: a topology generator for 3-D city models. ISPRS Journal of Photogrammetry and Remote Sensing, 53(5) 286-295. https://doi.org/10.1016/S0924-2716(98)00011-2

[10] Gruen, A., Huang, X., Qin, R., Du, T. Fang, W., Boavida, J., \& Oliveira, A. (2014). Joint processing of UAV imagery and terrestrial mms data for very high resolution 3D city modeling. GIS Science, 1, 10-20.

[11] Chou, T. Y., Yeh, M. L., Chen, Y., \& Chen, Y. H. (2010). Disaster monitoring and management by the unmanned aerial vehicle technology. Int. Arch. Photogram. Remote Sens. Spat. Inf. Sci., 38, 137-142.

[12] Colomina, I. \& Molina, P. (2014). Unmanned aerial systems for photogrammetry and remote sensing: A review, ISPRS J. Photogramm. Remote Sensing, 92, 79-97. https://doi.org/10.1016/j.isprsjprs.2014.02.013

[13] Feng, Q. (2014). UAV Remote sensing for urban vegetation mapping using random forest and texture analysis. Remote Sensing, 7(1), 1074-1094. https://doi.org/10.3390/rs70101074

[14] Niethammer, U., James, M. R., Rothmund, S., Travelletti, J., \& Joswig, M. (2012). UAV-based remote sensing of the super-sauze landslide: evaluation and results. Eng. Geol., 128, 2-11. https://doi.org/10.1016/j.enggeo.2011.03.012 
[15] (2014). Zoning and urban land use planning for drones. http://www.thehumanitarianspace.com/2014/08/zoningand-urban-land-use-planning-for.html/, (accessed 15.02.17).

[16] Everaerts, J. (2008). The use of unmanned aerial vehicles (UAVs) for remote sensing and mapping. Proc. The International Archives of the Photogrammetry, Remote Sensing Spatial Information Sciences XXXVII, Part B1, Beijing, China, 1187-1192.

[17] (2014). Drone Mapping for Urban Planning in Mexico City. https://www.mapbox.com/blog/flying-mexico-city/, (accessed 13.02.17)

[18] Pérez, M., Aguera, F., \& Carvajal, F. (2013). Low cost surveying using an unmanned aerial vehicle. Int. Arch. Photogramm. Remote Sens. Spat. Inf. Sci., 40, 311-315. https://doi.org/10.5194/isprsarchives-XL-1-W2-311-2013

[19] Remondino, F., Barazzetti, L., Nex, F., Scaioni, M., \& Sarazzi, D. (2011). UAV photogrammetry for mapping and 3D modeling-current status and future perspectives. Int. Arch. Photogram. Remote Sens. Spat. Inf. Sci., 38, 25-31.

[20] Jazayeri, I., Rajabifard, A., \& Kalantari, M. (2013). A geometric and semantic evaluation of $3 \mathrm{D}$ data sourcing methods for land and property information. Land Use Policy, 36, 219-230. https://doi.org/10.1016/j.landusepol.2013.08.004

[21] Smart, P., Quinn, J., \& Jones, C. (2011). City model enrichment. ISPRS Journal of Photogrammetry and Remote Sensing, 66(2), 223-234. https://doi.org/10.1016/j.isprsjprs.2010.12.004

[22] Qin, R., Gruen, A., \& Huang, X. (2012). UAV project building a reality-based 3D model of the NUS (National University of Singapore) campus. Proc. The ACRS2012, Pattaya, Thailand.

[23] Lucieer, A., Turner, D., King, D. H., \& Robinson, S. A. (2014). Using an unmanned aerial vehicle (UAV) to capture micro-topography of Antarctic moss beds. Int. J. Appl. Earth Obs. Geoinf., 27, 53-62. https://doi.org/10.1016/j.jag.2013.05.011

[24] Koutsoudis, A., Stravroglou, K., Pavlidis, G., \& Chamzas, C. (2013). 3DSSE: A 3D scene search engine, exploring 3D scenes using keywords. Journal of Cultural Heritage, 13(2), 187-194. https://doi.org/10.1016/j.culher.2011.09.001

[25] Harwin, S. \& Lucieer, A. (2012). Assessing the accuracy of georeferenced point clouds produced via multi-view stereopsis from unmanned aerial vehicle (UAV) imagery. Remote Sensing, 4, 1573-1599. https://doi.org/10.3390/rs4061573

[26] Gruen, A., Huang, X., Qin, R., Du, T., \& Fang, W. (2013). Integration of mobile laser scanning data with UAV imagery for very high resolution 3D city modeling. Proc. Symposium on Mobile Mapping Technology, Tainan, Taiwan.

[27] Li, D., Shan, J., Shao, Z., Zou, X., \& Yao, Y. (2013). Geomatics for smart cities -concept, key techniques and applications. Geo-Spatial Information Sciences, 16(1), 1324. https://doi.org/10.1080/10095020.2013.772803

[28] Pierrot Deseilligny, M. \& Clery, I. (2011). APERO, open source bundle adjustment software for automatic calibration and orientation of set of images. Proc. Int. Arch. Photogramm. Remote Sens. Spatial Inf. Sci., XXXVIII5/W16, Trento, Italy, 269-276.

[29] AgisoftPhotoScan. (2013). User manual: professional edition: version 0.9.1, AgiSoft LLC, Petersburg, Russia.

[30] Barazzett, L., Remondino, F., Scaioni, M., \& Brumana, R. (2010). Fully automatic UAV image-based sensor orientation. Proc. Int. Archives of Photogrammetry, Remote Sensing and Spatial Information Sciences, 38(1), Calgary, Canada.

[31] Verhoeven, G., Doneus, M., Briese, C., \& Vermeulen, F. (2012). Mapping by matching: a computer vision-based approach to fast and accurate georeferencing of archaeological aerial photographs. Journal of Archaeological Science, 39(7), 2060-2070. https://doi.org/10.1016/j.jas.2012.02.022

[32] Hülksen, F., Eckes, C., Kuck, R., Unterberg, J., \& Jörg, S. (2007). Modeling and animating virtual humans for real-time applications. International Journal of Virtual Reality, 6(4), 11-20.

[33] Manyoky, M., Theiler, P., Steudler, D., \& Eisenbeiss, H. (2011). Unmanned aerial vehicle in cadastral applications. Proc. ISPRS and UAV-g, Zurich, Switzerland.

[34] Robertson, D. \& Cipolla, R. (2009). Structure from motion. In Varga, M., editors, Practical image processing and computer vision. John Wiley, Hoboken, NJ, USA.

[35] Henry, J. B., Malet, J. P., Maquaire, O., \& Grussenmeyer, P. (2002). The use of small-format and low-altitude aerial photos for the realization of high-resolution DEMs in mountainous areas: application to the Super-Sauze earthflow (Alpes-de-HauteProvence, France), Earth Surf. Process. Landforms, 27(12), 1339-1350. https://doi.org/10.1002/esp.411

[36] Roca, D., Lagüela, S., Díaz-Vilariño, L., Armesto, J., \& Arias, P. (2013). Low-cost aerial unit for outdoor inspection of building façades. Autom. Constr., 36, 128-135. https://doi.org/10.1016/j.autcon.2013.08.020

[37] Becker, S. (2009). Generation and application of rules for quality dependent façade reconstruction. ISPRS Journal of Photogrammetry and Remote Sensing, 64(6), 640-653. https://doi.org/10.1016/j.isprsjprs.2009.06.002

\section{Contact information:}

Ramazan Cuneyt ERENOGLU, Assoc. Prof. Dr.

Canakkale Onsekiz Mart University,

Faculty of Engineering,

Department of Geomatics Engineering,

17020 Canakkale, Turkey

Tel: +90 (286) 2180018 (ext. 2206)

E-mail: ceren@comu.edu.tr

Oya ERENOGLU, Assist. Prof. Dr. Canakkale Onsekiz Mart University,

Faculty of Education,

Department of Geography Education,

17020 Canakkale, Turkey

Tel: +90 (286) 2180018 (ext. 3643)

E-mail: o turkdonmez@comu.edu.tr

Niyazi ARSLAN, Assoc. Prof. Dr.

Cukurova University,

Faculty of Ceyhan Engineering

Department of Geomatics Engineering,

Ceyhan Campus,

01950 Ceyhan, Adana, Turkey

Tel: +90 (322) 6137311

E-mail: narslan@cu.edu.tr 